\title{
Occurrence of arbuscular mycorrhizal fungi in the roots of two grapevine cultivars in response to bioproducts
}

\author{
Lidia Sas Paszt*, Sławomir Głuszek, Edyta Derkowska, Beata Sumorok, Jerzy Lisek, Paweł Trzciński, Anna Lisek, Mateusz \\ Frąc, Mirosław Sitarek, Michał Przybył
}

Research Institute of Horticulture, Skierniewice, Poland

Submitted for publication: July 2018

Accepted for publication: November 2018

Keywords: mycorrhizal frequency; 'Regent'; 'Solaris'; Vitis sp. (L.) wine-growing methods

The aim of this study was to determine the influence of different bioproducts on the occurrence of arbuscular mycorrhizal fungi (AMF) in the roots of 'Solaris' and 'Regent' grapevine cultivars. The following bioproducts were used, alone or with mineral fertilization (NPK): Ausma, Bioilsa, manure and BF Ekomix. The highest mycorrhizal frequency was recorded in the roots of 'Solaris' after applying the bioproduct Ausma. For the 'Regent' cultivar, the highest mycorrhizal frequency was found in the plants treated with Ausma, BF Ekomix and manure. Colonization of grapevine roots by AM fungi was limited by mineral fertilization. After the combined use of bioproducts and mineral fertilizers, there was observed a tendency for minimized negative effect of mineral fertilization on the formation of arbuscular mycorrhizal fungi.

\section{INTRODUCTION}

Fruits of the cultivars 'Regent' ('Diana' $\times$ 'Chambourcin') and 'Solaris' ['Merzling' x 'Geisenheim 6493' ('Zarya Severa' $\times$ 'Muscat Ottonel')] are mainly used for wine production. Both cultivars were bred in Germany and are classified as Vitis vinifera (L.) (Vitis International Variety Catalogue 2015) or as inter-intraspecific hybrids (Theocharis et al., 2010). 'Regent' and 'Solaris' have higher resistance to frost than most of the original $V$. vinifera varieties and have low susceptibility to fungal diseases (Lott et al. 2010; Lisek, 2012).

Both in Poland and abroad, bioproducts are increasingly being used in sustainable crop production (Sas Paszt et al., 2015). Agricultural bioproducts include diverse formulations of compounds, substances and other products that are applied to plants or soils to regulate and enhance the crop's physiological processes, thus making them more efficient. Microbial bioproducts act on plant physiology through pathways different from those of nutrients to improve crop vigour, yield, quality and post-harvest shelf storability (Verplancken, 2011). Bioproducts affect plants by exerting favourable effects on plant primary and secondary metabolism (Hause and Fester 2005; Jung et al. 2012). They stimulate the synthesis of natural hormones, facilitate the uptake of minerals from the soil, improve root growth, and also contribute to increasing the resistance to adverse environmental conditions (e.g. drought, frost and cold) (Sharma et al., 2014; Battacharyya et al., 2015; Van Oosten et al., 2017). The requirements to protect the natural environment and human health steer the agricultural production towards production by organic and environmentally friendly means. This leads to an increasing use of bioproducts, natural plant protection products and soil conditioners. Proper use of natural plant protection products and fertilizers in organic crop production is one of the key elements of their effectiveness.

Arbuscular mycorrhizal fungi (AMF) live in symbiosis with the majority of plant species on Earth (Öpik et al., 2006; Shahabivand et al., 2016). In many studies, AM fungi have been observed to have a positive effect on the growth and development of grapevines. For example, symbiotic fungi are involved in the uptake and transport of nutrient elements by the host plant (Cheng \& Baumgartner, 2006), and also increase water use efficiency (Valentine et al., 2006) and yielding of grapevines (Schreiner et al., 2007).

The numerous studies on grapevines have not examined the impact of bioproducts on the colonization of grapevine roots by arbuscular mycorrhizal fungi in field conditions. The aim of this study was to determine the effect of bioproducts on the colonization of grapevine roots by arbuscular mycorrhizal fungi under plantation conditions to develop sustainable wine-growing methods with the use of bioproducts of natural origin.

\section{MATERIALS AND METHODS}

Plants of 'Solaris' and 'Regent' grapevine cultivars, grafted on SO4 rootstock ( $V$. berlandieri $\mathrm{x} V$. riparia), were planted in the spring of 2008 in the Experimental Orchard of the Research Institute of Horticulture in Skierniewice (central

*Corresponding author: E-mail address: lidia.sas@inhort.pl

Acknowledgments: This work was supported by the Ministry of Science and Higher Education of Poland (project no. 5.2.4., statutory activities of the Research Institute of Horticulture) 
Poland) and trained in Double Guyot system with 10-14 bud canes and a low (0.3-0.4 m) trunk. The experiment was conducted in randomized complete blocks with 4 replications and 4 plants in each (16 vines per treatment and cultivar). The experimental combinations, arranged in a system of randomized blocks, were as follows: (1) Control combination - no NPK fertilization and no application of bioproducts. Mineral content of the soil ( $\mathrm{mg}$ x $100 \mathrm{~g}$ soil): $\mathrm{P}-10.3, \mathrm{~K}-$ 11.0, $\mathrm{Mg}-8.79, \mathrm{~B}-5.53, \mathrm{Cu}-6.98, \mathrm{Fe}-870, \mathrm{Mn}-121, \mathrm{Zn}$ - 4.78). (2) Mineral NPK fertilization - Ammonium nitrate was used at $70 \mathrm{~g}$ per plant, granular triple superphosphate at $77.5 \mathrm{~g}$ per plant, potassium sulfate at $97.5 \mathrm{~g}$ per plant. These doses of fertilizers were administered in April of each year. (3) Ausma (Biolat, Lithuania) - Plant product derived from steam-distilled pine needles, applied in a liquid form to the leaves- was used 3 times in the form of a foliar spray at a concentration of $0.1 \%$, at 9,6 , and 3 weeks before the fruit harvest. (4) Mineral NPK fertilization + Ausma in doses as above, at 9, 6, and 3 weeks before the fruit harvest. (5) Bioilsa (ILSA Group Arzignano, Italy) - product of animal origin, was applied in the form of granules at an amount of $24 \mathrm{~g}$ per plant to the soil in April of every year. (6) Mineral NPK fertilization + Bioilsa applied in doses as above. (7) Fertigo granulated manure (Dutch company Ferm-O-Feed) was applied at a rate of $25 \mathrm{~L}$ per plot $\left(5 \mathrm{~m}^{2}\right)$ in April of every year. (8) Mineral NPK fertilization + Fertigo manure applied in doses as above. (9) BF Ekomix - product of plant origin in the form of granules (AgroBio Products, NL) was applied at a rate of $100 \mathrm{~g}$ per plant to the soil in April of every year. (10) Mineral NPK fertilization + BF Ekomix in doses as above.

$10 \mathrm{~g}$ of roots from each replication were collected at the beginning of September in 2009-2014 and stained according to the method developed by Derkowska et al., (2013). The degree of colonization of grapevine roots by AM fungi was determined using the method of Trouvelot et al. (1986) with the use of a MYCOCALC program (http://www2.dijon.inra. fr/mychintec/Mycocalc-prg/download.html). The results were statistically analyzed using three-factorial analysis of variance with Tukey's test at a significance level of $\alpha=0.05$ using STATISTICA v.10 software (StatSoft Inc., 2011). The only AM fungi determined in this study were those naturally occurring in the grapevine roots, because all the applied bioproducts did not contain any introduced AM fungi.

\section{RESULTS AND DISCUSSION}

The study on the colonization of grapevine roots by arbuscular mycorrhizal fungi conducted in 2009-2014 indicates favourable effects of the bioproducts used on increasing mycorrhizal frequency in the roots of the cultivars tested (Table 1). In the first years of the experiment (20092011), the highest mycorrhizal frequency in the cultivar 'Solaris' was observed in the roots of plants treated with the bioproducts BF Ekomix and Ausma applied separately or together with NPK fertilization. In the final years of the experiment (2013-2014), the bioproduct Bioilsa was observed to have a positive effect on mycorrhizal frequency in plant roots. For the cultivar 'Regent', the most beneficial effect on mycorrhizal frequency in individual years of the experiment was exerted by the following bioproducts: BF Ekomix, manure, Ausma and Bioilsa, applied on their own

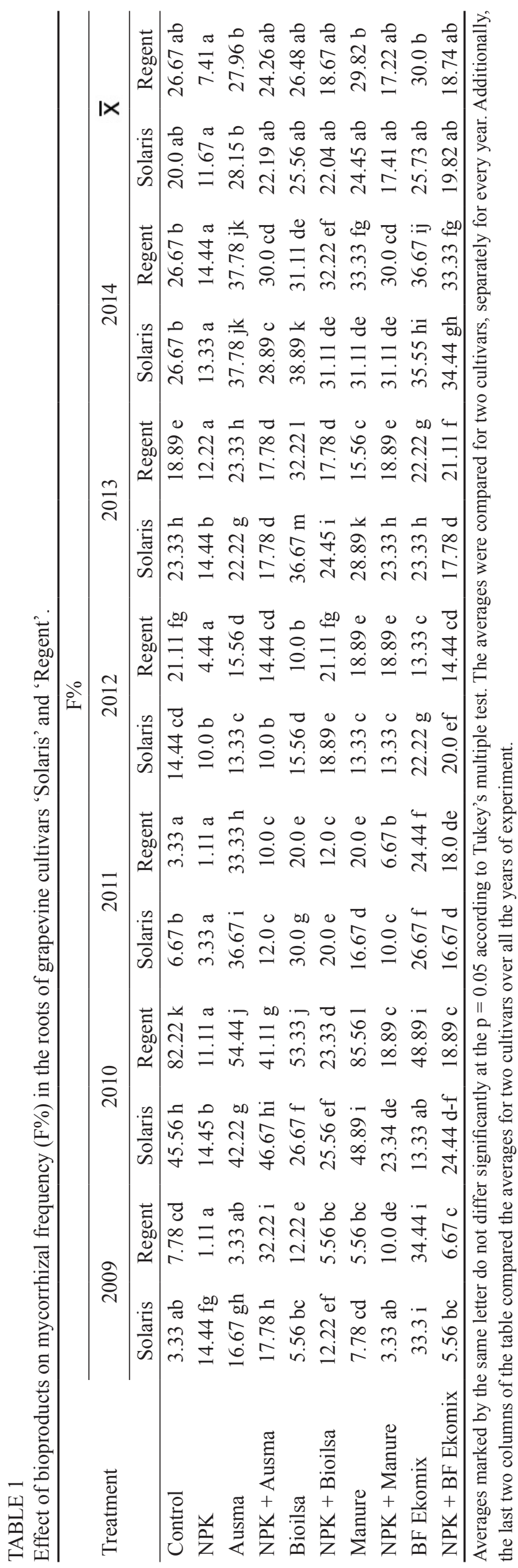


(without additional NPK fertilization). In contrast to the years 2009-2011 and 2013-2014, the highest mycorrhizal frequency recorded in 2012 was in the roots of plants treated with Bioilsa combined with NPK fertilization.

Compared with NPK treatment, the applied bioproducts and bioproducts combined with NPK fertilization contributed to increasing the colonization of roots by AM fungi. NPK fertilization limited to the greatest extent the degree of mycorrhizal association in the roots of 'Solaris' (11.7\%) and 'Regent' (7.4\%). The results for the six years of investigation show that the highest mycorrhizal frequency was recorded in the roots of 'Solaris' grapevines after applying the bioproduct Ausma (28.2\%). For 'Regent', the highest mycorrhizal frequency was observed in the plants treated with the bioproducts BF Ekomix (30.0\%), Ausma (27.9\%), and manure $(29.8 \%)$. The combined application of the bioproducts with NPK fertilization resulted in the lowering of the degree of mycorrhizal association in the roots of the grapevines in comparison with the use of the bioproducts alone. The data revealed that numerous vesicles in the roots of 'Solaris' and 'Regent' grapevine cultivars were formed after the application of the bioproduct Bioilsa, whereas single vesicles were detected in the roots of the plants under standard NPK fertilization (Figure 1, 2). Although the NPK treatment reduced mycorrhizal frequency in grapevine roots,

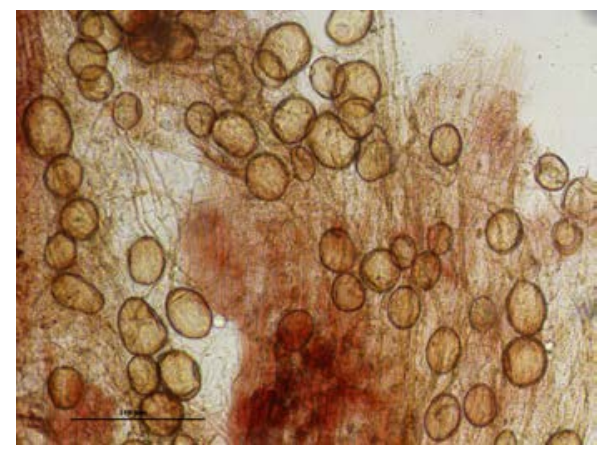

FIGURE 1

Numerous vesicles in the roots of a 'Regent' grapevine treated with bioproduct Bioilsa

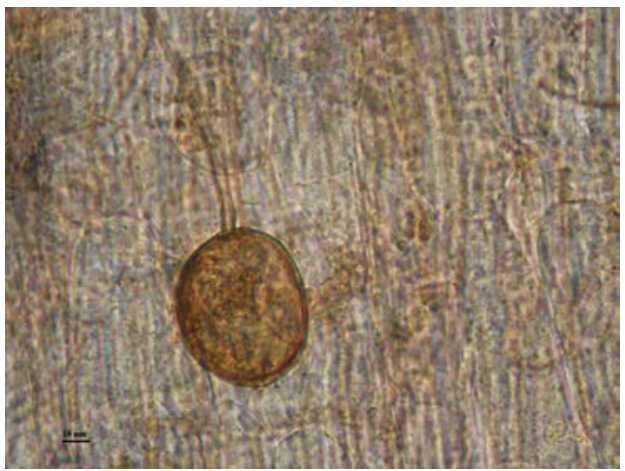

FIGURE 2

Single vesicles in the roots of a 'Regent' grapevine fertilized with NPK the mycorrhizal frequencies for NPK and the control without application of bioproducts did not differ significantly. The NPK treatment also did not differ significantly with regard to mycorrhizal frequency after application of the bioproducts except for Ausma on 'Regent' and 'Solaris' and BF Ekomix on 'Regent'.

In this study, the species of arbuscular mycorrhizal fungi were identified in the rhizosphere of cultivars 'Regent' and 'Solaris' based on the morphological traits of their spores: Funneliformis caledonium, Glomus aggregatum, Glomus macrocarpum, Rhizophagus intraradices, Claroideoglomus claroideum and Gigaspora margarita (data not presented).

The results from the individual years of the study and 6-year averages confirmed the negative impact of NPK fertilization in mycorrhizal frequency in the roots of both grapevine cultivars tested. The use of bioproducts, such as Ausma, Bioilsa, BF Ekomix and manure, seems to partly reverse the negative effect of inorganic fertilization on the colonization of roots by mycorrhizal fungi, though the differences between mycorrhizal frequency $(\mathrm{F} \%)$ in the roots after NPK fertilization and NPK fertilization with bioproducts were not statistically significant. Mycorrhizal frequency in the roots of the grapevines was low at the average level. Low mycorrhizal frequency has also been observed in the roots of apple $(2.5 \%$ to $25.8 \%$ ) and blackcurrant plants (0 to $11.1 \%)$ treated with organic mulches (Sumorok et al., 2011; Derkowska et al., 2013). Petit and Gubler (2006) recorded higher colonization of roots at a level of $48.3 \%$ in the plants of Vitis rupestris inoculated with Rhizophagus intraradices, and at 54.5\% in the plants inoculated with Rhizophagus intraradices and the pathogenic fungus Cylindrocarpon macrodidymum. A factor that is of significance to mycorrhizal frequency in the roots of grapevines is soil moisture. The water content of the soil, weather conditions, frequency of irrigation or its absence all have a significant impact on mycorrhizal frequency in the roots of grapevine plants (Augé, 2004; Schreiner et al. 2007).

Mycorrhizal frequency in the roots of plants is also significantly affected by soil fertility in terms of mineral and organic matter content, and by soil $\mathrm{pH}$. The lowest frequency was observed in the combination fertilized with NPK, and it might have been influenced by the form of the nitrogen fertilizer used, containing both nitrate and ammonium ions, which more strongly limit the colonization of roots by AMF. Reductions in mycorrhizal frequency under the influence of ammonium ions have been observed by other authors (Guo et al., 2006; Karagiannidis et al., 2007). It has also been found that the presence of phosphate in the soil or application of phosphorous fertilizers reduces AMF frequency/colonization in plant roots. Frequency of occurrence, relative abundance, species richness and diversity index of AM fungi were higher in low-P soils than in high-P soils (Harikumar and Potty 2012).

Moreover, mycorrhizal frequency is also affected by the $\mathrm{pH}$ of the soil - it is lower at a lower $\mathrm{pH}$ (Wang et al., 1993). Application of the bioproduct Bioilsa increased the number of vesicles in the roots of both grapevine cultivars tested compared to the plants under standard NPK fertilization. The use of manure and bioproducts, such as: Ausma, Bioilsa and BF Ekomix, seems to reverse the negative effect of mineral fertilization on the colonization of roots by mycorrhizal 
fungi. Research in this area will be continued in order to determine the impact of bioproducts on the occurrence of beneficial groups of microorganisms in the microbiome of the grapevine cultivars studied and on the growth and yielding of plants. This will help to develop sustainable wine-growing methods with the use of bioproducts of natural origin.

\section{CONCLUSIONS}

Application of the bioproduct Bioilsa resulted in the formation of numerous vesicles in the roots of 'Solaris' and 'Regent' grapevine cultivars. Colonization of grapevine roots by mycorrhizal arbuscular fungi was decreased to the greatest extent by mineral NPK fertilization. The use of manure and bioproducts, such as: Ausma, Bioilsa, BF Ekomix seems to reverse the negative effect of mineral fertilization on the colonization of roots by mycorrhizal fungi.

\section{LITERATURE CITED}

Augé, R. M. 2004. Arbuscular mycorrhizae and soil/plant water relations. Can. J. Soil Sci. 84(4):373-381.

Battacharyya, D., Babgohari, M.Z., Rathor, P., Prithiviraj, B. 2015. Seaweed extracts as biostimulants in horticulture. Scientia Horticulturae 196: 39-48.

Cheng, X., Baumgartner, K., 2006. Effects of mycorrhizal roots and extraradical hyphae on ${ }^{15} \mathrm{~N}$ uptake from vineyard cover crop litter and the soil microbial community. Soil Biol. Biochem. 38:2665-2675.

Derkowska, E., Sas Paszt L., Sumorok B. \& Dyki B., 2013. Colonisation of apple and blackcurrant roots by arbuscular mycorrhizal fungi following mycorrhisation and the use of organic mulches. Folia Horticulturae 25:117122 .

Guo, T., Zhang, J., Christie, P. \& Li, X., 2006. Effects of arbuscular mycorrhizal fungi and ammonium: nitrate ratios on growth and pungency of onion seedlings. J. Plant Nutr. 29: 1047-1059.

Harikumar, V. S., \& Potty, V. P. 2012. Arbuscular mycorrhizal associations and its influence on phenotypic and growth characters of sweet potato genotypes under varied soil phosphorus availability. J. Trop. Agric. 89(4).

Hause, B. \& Fester, T. 2005. Molecular and cell biology of arbuscular mycorrhizal symbiosis. Planta 221:184-196.

Jung, S. C., Martinez-Medina, A., Lopez-Raez, J. A., \& Pozo, M. J. 2012. Mycorrhiza-induced resistance and priming of plant defenses. J. Chem. Ecol. 38(6): 651-664.

Karagiannidis, N., Nikolaou, N., Ipsilantis, I. \& Zioziou, E. 2007. Effects of different $\mathrm{N}$ fertilizers on the activity of Glomus mosseae and on grapevine nutrition and berry composition. Mycorrhiza 18: 43-50.

Lisek, J. 2012. Winter frost injury of buds on one-year-old grapevine shoots of Vitis vinifera cultivars and interspecific hybrids in Poland. Folia Horticulturae 24(1): 97-103.

Lott H., Pfaff F., Prior B., 2010. Taschenbuch der Rebsorten. 13 Auflage. Fachverlag Dr. Fraund GmbH, Mainz, 385 pp.
Öpik, M., Moora, M., Liira, J. \& Zobel, M., 2006. Composition of rootcolonizing arbuscular mycorrhizal fungal communities in different ecosystems around the globe. J. Ecol. 94: 778-790.

Petit, E. \& Gubler, W.D. 2006. Influence of Glomus intraradices on Black Foot disease caused by Cylindrocarpon macrodidymum on Vitis rupestris under controlled conditions. Plant Dis. 90: 1481-1484.

Sas Paszt, L., Malusa, E., Sumorok, B., Canfora, L., Derkowska, E. \& Głuszek S., 2015. The influence of bioproducts on mycorrhizal occurrence and diversity in the rhizosphere of strawberry plants under controlled conditions. Adv. Microbiol. 5: 40-53.

Shahabivand, S., Maivan, H. Z., Mahmoudi, E., Soltani, B. M., Sharifi, M. \& Aliloo, A. A., 2016. Antioxidant activity and gene expression associated with cadmium toxicity in wheat affected by mycorrhizal fungus. Zemdirbyste 103: 53-60.

Sharma, H.S., Fleming, C., Selby, C., Rao, J.R. \& Martin, T. 2014. Plant biostimulants: a review on the processing of macroalgae and use of extracts for crop management to reduce abiotic and biotic stresses. J. Appl. Phycol. 26(1): 465-490.

Schreiner, R., Tarara, J. \& Smithyman, R., 2007. Deficit irrigation promotes arbuscular colonization of fine roots by mycorrhizal fungi in grapevines (Vitis vinifera L.) in an arid climate. Mycorrhiza 17: 551-562.

StatSoft, I.N.C. 2011. STATISTICA (data analysis software system) version 10. Tulsa.

Sumorok, B., Sas Paszt, L., Głuszek, S., Derkowska, E. \& Żurawicz, E., 2011. The effect of mycorrhization and mulching of apple trees 'Gold Milenium' and blackcurrant bushes 'Tiben' on the occurrence of arbuscular mycorrhizal fungi. J. Fruit Ornam. Plant Res. 19: 35-49.

Theocharis, A., Hand, P., Pole, J., Cevik, V., Fisarakis, I. \& Henderson, J., 2010. Study of genetic diversity among inter-intraspesific hybrids and original grapevine varieties using AFLP molecular markers. Aust. J. Crop Sci., 4: 1-8.

Trouvelot, A., Kough J-L. \& Gianinazzi-Pearson., V., 1986. Mesure du taux de mycorhization VA d'un systeme radiculaire. Recherche de méthodes d'estimation ayant une significantion fonctionnelle. Gianinazzi-Pearson V., Gianinazzi S., (eds). Physiological and Genetical Aspects of Mycorrhizae. Proceedings of the 1st European Symposium on mycorrhizae. Dijon, France, pp. 217-221.

Valentine, A.J., Mortimer, P.E., Lintnaar, M. \& Borgo, R., 2006. Drought responses of arbuscular mycorrhizal grapevines. Symbiosis 41: 127-133.

Van Oosten, M.J., Pepe, O., De Pascale, S., Silletti, S. \& Maggio A. 2017. The role of biostimulants and bioeffectors as alleviators of abiotic stress in crop plants. Chem. Biol. Technol. Agric. 4(1): 5.

Verplancken, B., 2011. Biostimulants definition agreed. European Biostimulants Industry Council (EBIC). http://www.biostimulants. eu/2011/10/biostimulants-definition-agreed/

Wang, G.M., Stribley, D.P., Tinker, P.B. \& Walker, C., 1993. Effects of pH on arbuscular mycorrhiza I. Field observations on the long-term liming experiments at Rothamsted and Woburn. New Phytol., 124: 465-472.

Vitis International Variety Catalogue., 2015. http://www.vivc.de/ 